Sammlung Metzler

Band 217 


\author{
Jürgen Schutte
}

\title{
Einführung in die Literaturinterpretation
}

3., überarbeitete und erweiterte Auflage 
Die Deutsche Bibliothek - CIP-Einheitsaufnahme

\section{Schutte, Jürgen:}

Einführung in die Literaturinterpretation /

Jürgen Schutte. - 3., überarb. und erw. Aufl.

- Stuttgart; Weimar : Metzler, 1993

(Sammlung Metzler ; 217)

ISBN 978-3-476-13217-8

NE: GT

ISSN 05583667

ISBN 978-3-476-13217-8

ISBN 978-3-476-04125-8 (eBook)

DOI 10.1007/978-3-476-04125-8

SM 217

Dieses Werk einschließlich aller seiner Teile ist urheberrechtlich geschützt. Jede Verwertung außerhalb der engen Grenzen des Urheberrechtsgesetzes ist ohne Zustimmung des Verlages unzulässig und strafbar. Das gilt insbesondere für Vervielfältigungen, Übersetzungen, Mikroverfilmungen und die Einspeicherung und Verarbeitung in elektronischen Systemen.

(C)1993 Springer-Verlag GmbH Deutschland

Ursprünglich erschienen bei J. B. Metzlersche Verlagsbuchhundlung und Carl Ernst Poeschel Verlag GmbH in Stuttgart 1993 


\section{INHALT}

EINLEITUNG $\ldots \ldots \ldots \ldots \ldots \ldots \ldots \ldots \ldots \ldots \ldots \ldots, \quad 1$

1. Literaturaneignung als kommunikative Praxis .... . 5

1.1. Lektüre-Kritik - Interpretation: Formen der Aneignung . . . 5

1.2. Methodische Praxis der Interpretation $\ldots \ldots \ldots \ldots \ldots \ldots$

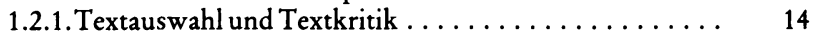

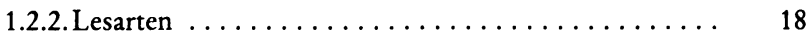

1.2.3. Hermeneutischer Exkurs . . . . . . . . . . 20

1.2.4. Arbeitsschritte einer methodischen Interpretation . . . 29

1.3. Modell der literarischen Kommunikation ........... 35

2. WIRKLICHKEIT - AUTOR - TEXT:

ProduktionsÄsthetische AnAlyse ............. 44

2.1. Der Text als Botschaft des Autors und Zeugnis seiner

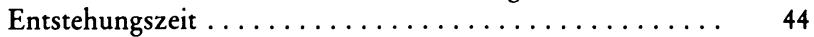

2.2. Modell der Textproduktion ............... 53

2.3. Zugänge zur produktionsästhetischen Analyse ........ 61

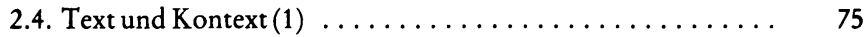

3. Kategorien Und Verfahren der Strukturanalyse . . 94

3.1. Der Text als Struktur . . . . . . . . . . . . . . . . . 94

3.2. Kategorien der Inhaltsanalyse . . . . . . . . . . . . . 108

3.3. Strukturanalyse narrativer Texte . . . . . . . . . . . 118

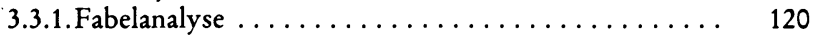

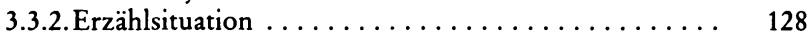

3.4. Strukturanalyse lyrischer Texte . . . . . . . . . . 137

4. TEXT - LESER - WIRKLICHKEIT:

Rezeptionsästhetische ANALYSE . . . . . . . . . . . 156

4.1. Der literarische Text als Rezeptionsvorgabe $\ldots \ldots \ldots \ldots .156$

4.2. Modell der Textrezeption .................. 166

4.3. Zugänge zur rezeptionsästhetischen Analyse ........... 175

4.4. Text und Kontext (2) .................... 190

ANHANG: Hinweise zur Technik des wissenschaftlichen

Arbeitens ......................... 198

LITERATURVERZEICHNIS $\ldots \ldots \ldots \ldots \ldots \ldots \ldots \ldots \ldots, 212$

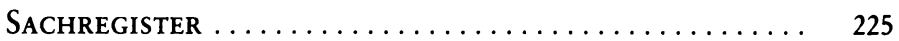




\section{VORBEMERKUNG}

Die Verhältnisse an den Hochschulen der Bundesrepublik und West-Berlins, ganz besonders im >Massenfach (Germanistik, sind nicht so, daß größere Forschungsarbeiten ohne fast unzumutbare zusätzliche Belastungen durchgeführt und abgeschlossen werden könnten. Die seit Jahren andauernde ,Überlast «-Situation, der Stellenabbau im wissenschaftlichen und nicht-wissenschaftlichen Personal und die drohende Zerstörung aller beruflichen und sozialen Perspektiven für den wissenschaftlichen Nachwuchs und die Studierenden überhaupt zwingen einen mehr, als das gut wäre, zur Improvisation. Um so nachdrücklicher möchte ich allen danken, die mir bei der Ausarbeitung des hier vorgelegten Versuchs mit Rat und Freundlichkeit geholfen haben. Das betrifft vor allem die Studentinnen und Studenten, Kolleginnen und Kollegen, mit denen ich einzelne Teile und Aspekte diskutieren konnte, besonders Helmut Peitsch, Peer Ball und Hans Jürgen Bachorski. Marlene Stukowske hat mit großer Sorgfalt und Geduld das Typoskript angefertigt, Ulrike Faber den größten Teil der persönlichen Belastungen aufgefangen. Der Abschluß der Arbeit wurde durch einen Forschungszuschuß der Freien Universität Berlin wesentlich erleichtert; in diesem Rahmen hat Joachim Wohlfeil an der Fertigstellung des Textes mitgearbeitet.

West-Berlin, November $1984 \quad$ J.S.

\section{ZUR ZITIERWEISE}

Zitate und Verweise im Text werden mit dem Erscheinungsjahr und der Seite der Quelle genannt; die Angaben beziehen sich durchgehend auf das Literaturverzeichnis S. $212 \mathrm{ff}$. 